\title{
Ruth Amar, Du regard autre et de la solitude dans l'œuvre le clézienne
}

\section{Davide Gambino}

\section{Q OpenEdition}

10 Journals

\section{Édition électronique}

URL : https://journals.openedition.org/studifrancesi/41278

DOI : $10.4000 /$ studifrancesi. 41278

ISSN : 2421-5856

Éditeur

Rosenberg \& Sellier

\section{Édition imprimée}

Date de publication : 1 juillet 2004

Pagination : 224-225

ISSN : 0039-2944

\section{Référence électronique}

Davide Gambino, "Ruth Amar, Du regard autre et de la solitude dans l'œuvre le clézienne », Studi Francesi [En ligne], 142 (XLVIII | I) | 2004, mis en ligne le 30 novembre 2015, consulté le 09 septembre 2021. URL : http://journals.openedition.org/studifrancesi/41278; DOI : https://doi.org/10.4000/ studifrancesi. 41278

Ce document a été généré automatiquement le 9 septembre 2021.

\section{(c)}

Studi Francesi è distribuita con Licenza Creative Commons Attribuzione - Non commerciale - Non opere derivate 4.0 Internazionale. 


\title{
Ruth Amar, Du regard autre et de la solitude dans l'œuvre le clézienne
}

\author{
Davide Gambino
}

\section{RÉFÉRENCE}

RUTH AMAR, Du regard autre et de la solitude dans l'œuvre le clézienne, «Les lettres romanes», 2001- LV, pp.9-17.

1 Cet article est consacré au lien intime et presque biunivoque unissant le regard (que Le Clézio dénomme «autre») indépendant, voire surhumain du cosmos, et la solitude comme conséquence et en même temps origine de cette altérité. Le bref essai se structure autour d'un passage en revue des tropes et autres métaphores des récits le cléziens ayant cette thématique comme point de convergence.

2 Sur le plan de l'objet on aborde la comparaison, voire même l'identification des concepts abstraits de l'œil «autre» et du cercle, élément variable trouvant ses hypostases ontologiques dans le serpent qui, enroulé sur lui-même devient à la fois symbole du cycle perpétuel de l'Univers et de la chute du rapport avec l'extérieur; autre élément fondamental, le soleil, qui partage avec l'œil la même terminaison orthographique et la même forme circulaire éternellement porteuse de perfection et conséquemment de solitude. Les deux idées d'œil cosmique et de solitude se trouvent unies par le truchement d'un symbole tout aussi conceptuel: le cercle.

3 Sur le plan de la personne en revanche ce lien est cristallisé dans la différence, l'exclusivité de l'être qui de par sa propre condition surhumaine ou grâce aux répercussions du regard «autre» sur sa personnalité, a le pouvoir de semer la solitude autour de lui. Ces personnages «autres» ou "privilégiés» deviennent ainsi les reflets animés de l'œil avide, autoréférentiel, donc insatisfait du Cosmos.

4 Pour appuyer ses considérations, l'A. se réfère en outre à une image tirée du recueil de Michaux Chemins cherchés, Chemins perdus, transgressions, et à un passage de La solitude essentielle de Blanchot qui propose une implication de l'idée de fascination. 
5 En bref, l'A. ne se contente pas d'énoncer les hypostases du binôme le clézien de regard «autre» et solitude, tant sur le plan des symboles que sur celui des personnages; elle procède également à une réflexion globale sur l'argument, en cherchant à en dégager les lignes de force et les répercussions sur les auteurs ayant affronté de près la même sujet. 